\title{
SPACEFARER SOLAR KITES FOR SOLAR SYSTEM EXPLORATION
}

\section{Jack}

\author{
Kingston University, United Kingdom
}

\section{R Wall}

EADS Astrium Ltd, United Kingdon

\author{
C S Welch \\ Kingston University, United Kingdom
}

\begin{abstract}
$\underline{\text { Abstract }}$
A solar kite is a small rigid solar sail with an area of a few square metres, capable of carrying a payload of a few hundred grams. In contrast to more ambitious solar sails, a kite can be deployed from its canister by a simple spring-driven mechanism. Because of its very small moment of inertia, a kite can be steered by quasipassive means. This paper summaries the findings of an ESA-funded research project examining the design, construction and deployment of solar kites, together with the missions they are capable of undertaking and the science data that could be obtained through their use. It focuses in particular on the high performance 'Spacefarer' kite capable of progressing from GTO to near-Earth targets including the Moon, Lagrange points and asteroids.
\end{abstract}

Keywords: ‘solar kite’, solar sailing', picosat, MEMS, imaging

\section{$\underline{1 \text { - Introduction }}$}

A solar is kite is a micro solar sail with mass of a few kilograms, a diameter of a few meters, controlled using a minimum of moving parts which has been the subject of earlier papers by the authors [1], [2]. This paper reports on the outcomes of a European Space Agency-funded study, one purpose of which was to determine whether useful missions could be found for kites.

\section{$\underline{2 \text { - Solar kite mission regimes }}$}

It is potentially feasible to launch a solar kite to Low Earth Orbit (LEO), to higher orbits, such as Geostationary Transfer Orbit (GTO), or as a passenger on an interplanetary mission. Each of these mission regimes has particular characteristics that affect the sort of kite missions that might be possible in it.

LEO is a hostile environment for kites. A kite is particularly vulnerable to atmospheric drag unless it has an apogee of at least $700 \mathrm{~km}$ (which limits low-cost launch opportunities). A kite in LEO also suffers from frequent eclipses and from high tidal torques. Rapid change in the optimal propulsion angle places heavy demands on the manoeuvring system. Additionally, there are few useful missions for a kite in LEO, and climbing to higher orbits takes a long time and incurs a high radiation dose.

From GTO, mission times and radiation doses to reach distances ranging from a few hundred thousand to a few million km are acceptable. Furthermore, data can be returned to Earth over a direct communication link and relatively low-cost 'piggyback' launch opportunities to GTO are also available using, for example, a microsat or minisat bay on the Ariane-5 ASAP auxiliary payload bus.

A solar kite is also capable of undertaking an interplanetary mission. However, to do so would require two significant problems to be overcome. These are, firstly, the duration of the mission and, secondly (and possibly the more serious of the two), the necessity to maintain a communications link with Earth. These problems can be obviated by carrying one or more kites on a 'mother ship', which will deploy them later and act as a relay for communications. Although certainly interesting in the longer term, the authors consider that this is not appropriate for kite missions until the concept has been proved and have focused on the opportunities that kites 
present for exploration of the Moon, Lagrange points and Near-Earth Asteroids.

\section{$\underline{3 \text { - Kite scientific payloads }}$}

The kite payload mass limitation restricts the useful science instruments that a kite can carry quite substantially. Any instruments must not only be of low mass and power consumption but, since very little shielding can be carried, also very radiation resistant.

During the study, only one instrument fully satisfying these requirements was found - the FillFactory STAR250 CMOS-based imaging chip [3]. This device can be used in cameras of various designs with applications including:

- High-resolution imaging - returning close-up images of lunar surface, near-Earth asteroids, etc.

- High-resolution multispectral imaging - in conjunction with a linear variable interference filter.

Where the field-of-view (FOV) requirement is similar, the same physical camera can perform several roles. For example, it could be used both for attitude control and navigation as well as for data collection. It would also be feasible for the kite to carry several cameras with different optics (lenses, filters, etc.) all of which use exactly the same type of chip as their image sensor. As a result, the same electronics, switchable between cameras, could then provide control and frame grabbing capabilities for all of them.

\section{4 - Solar kite missions}

During the study, four types of high-value mission were identified for a solar kite using a capable imager such as the STAR-250, with two other mission concepts also being proposed for future evaluation.

\section{$\underline{4.1 \text { - Lunar surface imaging }}$}

A kite can readily enter a highly elliptical lunar orbit with a very low perigee - as low as a few hundred meters. With modest optics, and without slewing, it can capture images of the lunar surface of resolution down to 15 $\mathrm{cm}$. Also, unlike other types of spacecraft, a kite can continuously tune its orbit without consuming fuel, so compensating for the effects of mascons and similar, and select different targets for each perilune approach.

\section{2 - Lunar surface multispectral imaging}

In conjunction with a linear interference filter, a solar kite can capture multispectral images of the lunar surface. The exposure time must be increased by approximately 50 to compensate for the reduced number of photons available to each pixel, so achievable resolution is about 7.5 metres; the same patch of ground is photographed up to 512 times through different rows of pixels filtered at different peak wavelengths as the kite passes over.

\section{3 - Imaging at high lunar latitudes}

Permanently dark lunar craters at the lunar poles are difficult or impossible to image using conventional spacecraft. Such areas are of great interest, however, as they may contain frozen volatiles. A kite flying over the lunar poles could be tilted so as to reflect sunlight downwards, providing the equivalent of a powerful searchlight. Surfaces which are normally permanently dark, or poorly illuminated, can be imaged at high resolution and even with multispectral capability. At 500 metres altitude the kite could reflect an illumination equivalent to $\sim 0.1$ natural sunlight on a spot immediately below it.

\section{$\underline{4.4 \text { - Imaging of NEO objects }}$}

A kite could perform a flyby of a Near Earth Object (NEO), or of several NEOs consecutively, returning pictures including multispectral images. The resolution would depend on the flyby speed and distance selected. 
The time necessary to transmit each picture would be long (days per picture, compared to approximately one hour per picture at lunar distance) but a selection of images could be transmitted during the months necessary for the kite to reposition itself for each successive target.

\section{$\underline{4.5}$ - Detection of dust at the Earth-Moon L4/L5 Lagrange points}

It has been hypothesised that meteoric dust may collect at the stable Earth-Moon Lagrange points (L4 and L5). A kite could also perform a slow flyby of these during which its camera could detect particles down to less than one micrometer in size. The size and mass of any particles detected could be inferred from both their apparent speed and their tendency to be accelerated by reflected light from the kite's surface.

\section{$\underline{4.6 \text { - Dust sample return }}$}

Due to its small size and low mass per unit area, a kite is intrinsically able to re-enter the Earth's atmosphere at relatively modest temperatures and g-forces $\left(\sim 230^{\circ} \mathrm{C}, 10 \mathrm{~g}\right)$. An otherwise unmodified kite with a Kapton sail should be able to return a dust sample to soft landing on Earth.

\section{$\underline{5 \text { - Solar kite launch and trajectory analysis }}$}

\section{$\underline{5.1 \text { - Implications of deployment altitude }}$}

Ariane 5 GTO has been selected as the deployment orbit. The authors have been informed that future Ariane 5 launches to GTO will use a lower perigee of $250 \mathrm{~km}$ ( $600 \mathrm{~km}$ has been used hitherto). This does not significantly affect kite mission times. However it does have potential implications for atmospheric re-entry in the first stages of the flight, as described in the next section.

\section{$\underline{5.2 \text { - Minimum deployment altitude }}$}

Atmospheric density at $250 \mathrm{~km}$ altitude varies significantly with time and the solar cycle, normally in the range $4-12 \times 10^{-14} \mathrm{~g} / \mathrm{cm}^{3}$. A kite with an areal density of $100 \mathrm{~g} / \mathrm{m}^{2}$ can be deccelerated at $\sim 0.1 \mathrm{~m} / \mathrm{s}^{2}$ at perigee in the maximum density case. However, perigee is of brief duration, so the total velocity loss will only be $\sim 30 \mathrm{~m} / \mathrm{s}$. This would cause atmospheric re-entry after approximately 100 orbits. However a kite of this areal density can also accelerate under solar thrust near apogee, gaining $\sim 1 \mathrm{~m} / \mathrm{s}$ apogee velocity per orbit. Thus the kite can raise its perigee altitude by around $12 \mathrm{~km}$ on each successive orbit.

Velocity loss at perigee reduces apogee altitude, while leaving perigee altitude effectively unaltered. Velocity gain at apogee raises perigee altitude, while leaving apogee altitude unaltered. Thus perigee velocity loss reduces by about one-third with each successive orbit, and becomes negligible after about 10 orbits, before the apogee altitude has time to reduce significantly.

\section{$\underline{5.3 \text { - Trajectory analysis }}$}

\subsection{1 - GTO Escape Times}

Escape times were determined using a high-fidelity simulation with analytical sail steering laws. These steering laws maximise the rate of orbit energy gain, while avoiding a drop in perigee altitude and produce near timeoptimal trajectories. In all cases an initial geostationary transfer orbit (GTO) of $250 \mathrm{~km}$ x 35,786 km x $5.33 \mathrm{deg}$ was used. Two configurations were assumed corresponding to a Sun-pointing apogee and Sun-pointing perigee. In addition, a solar kite characteristic acceleration of $0.1 \mathrm{~mm} \mathrm{~s}^{-2}$ and $0.2 \mathrm{~mm} \mathrm{~s}^{-2}$ has been assumed. With these assumptions the following escape times are found, detailed in Table 1 below. A typical escape spiral is also shown in Figure 1. 


\begin{tabular}{|lr|lc|ll|}
\hline $\begin{array}{l}\text { Sail } \\
\text { Characteristic } \\
\text { Acceleration }\end{array}$ & $\begin{array}{l}\text { Escape Time } \\
\text { (Sun-pointing } \\
\text { apogee) }\end{array}$ & $\begin{array}{l}\text { Escape Time } \\
\text { (Sun-pointing } \\
\text { perigee) }\end{array}$ \\
\hline 0.1 & $\mathrm{~mm} \mathrm{~s}^{-2}$ & $1072.9 \quad$ Days & 999.6 & days \\
\hline 0.2 & $\mathrm{~mm} \mathrm{~s}^{-2}$ & 570.7 & Days & 501.3 & days \\
\hline
\end{tabular}

Table 1 - Escape time from GTO

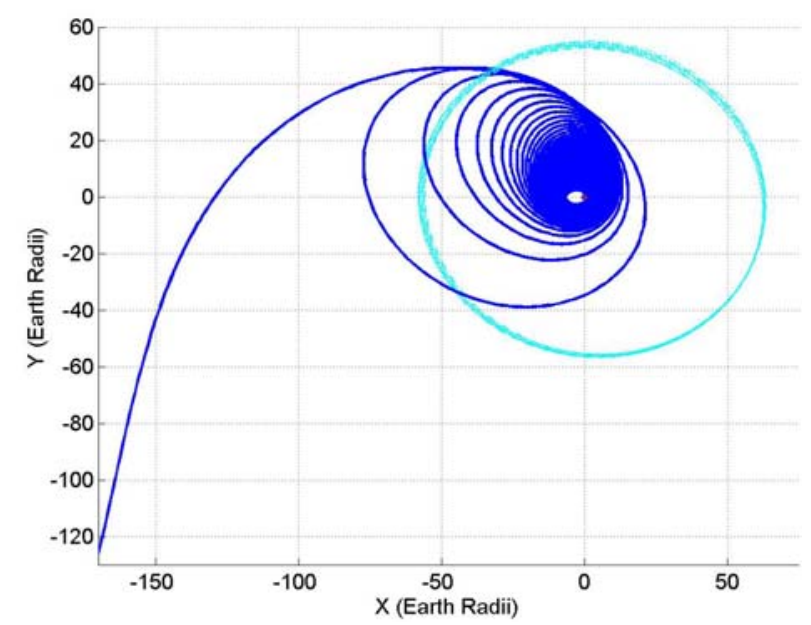

Figure 1 - Escape from GTO with sail acceleration $0.2 \mathrm{~mm} / \mathrm{s}^{2}$ (Sun-pointing perigee)

\subsection{2 - Lunar Transfer Times}

Full calculation of lunar transfer times requires a complex 3-body analysis which was outside the scope of the ESA study. Approximate times were found by calculating the time required to reach the lunar distance from GTO, and the time required to capture into the final parking orbit at the Moon. The final orbit is assumed to be a $4 \mathrm{hr}$ orbit period with $0 \mathrm{~km}$ perilune altitude, which then gives the apolune altitude as $\sim 2440 \mathrm{~km}$. Approximate transfer and capture times are shown in Table 2 and Table 3. The variation in transfer time arises from the eccentricity of the Moon's orbit, and hence the start date of the transfer from GTO.

\begin{tabular}{|lc|lc|}
\hline \multicolumn{2}{|l|}{$\begin{array}{l}\text { Sail Characteristic } \\
\text { Acceleration }\end{array}$} & & \multicolumn{2}{|l|}{ Transfer Time } \\
\hline 0.1 & $\mathrm{~mm} \mathrm{~s}^{-2}$ & $630-700$ & Days \\
\hline 0.2 & $\mathrm{~mm} \mathrm{~s}^{-2}$ & $300-350$ & Days \\
\hline
\end{tabular}

Table 2 - Approximate time required for GTO-lunar transfer

\begin{tabular}{|ll|ll|}
\hline $\begin{array}{l}\text { Sail Characteristic } \\
\text { Acceleration }\end{array}$ & Capture Time \\
\hline 0.1 & $\mathrm{~mm} \mathrm{~s}^{-2}$ & 390 & Day \\
& & $\mathrm{s}$ \\
\hline 0.2 & $\mathrm{~mm} \mathrm{~s}^{-2}$ & 181 & Day \\
& & & $\mathrm{s}$ \\
\hline
\end{tabular}


Table 3 - Approximate time required for lunar capture

In addition, the time required to reach the Earth-Moon $\mathrm{L}_{4}$ and $\mathrm{L}_{5}$ points is close to the time required to reach the lunar distance, given that the points are equilateral. Detailed analysis was again a complex 3-body analysis outside the scope of the study.

\subsection{3 - Precessing Lunar Trajectories}

Again, the final orbit is assumed to be a 4-hour orbit period with $0 \mathrm{~km}$ perilune altitude, which again gives the apolune altitude as $\sim 2440 \mathrm{~km}$. The remainder of the orbital elements are set up such that the perilune is above the lunar northern pole, the orbit inclination is $90^{\circ}$ and the orbit normal is parallel to initial Moon-Sun line, as shown in Figure 2. The time required to manoeuvre the perilune in various directions is listed in Table 4.

\begin{tabular}{|c|c|c|}
\hline $\begin{array}{l}\text { Sail } \\
\text { Characteristic } \\
\text { Acceleration }\end{array}$ & $\begin{array}{l}\text { Orbit inclination } \\
\text { varied by } 1 \text { deg }\end{array}$ & $\begin{array}{l}\text { Argument of } \\
\text { perilune varied } \\
\text { by } 1 \mathrm{deg}\end{array}$ \\
\hline $0.1 \quad \mathrm{~mm} \mathrm{~s}^{-2}$ & $\begin{array}{ll}\text { (negative) } & \\
8.2 & \text { days } \\
\text { (positive) } & \\
8.9 & \text { days }\end{array}$ & $\begin{array}{ll}\text { (negative) } & \\
1.98 & \text { days } \\
\text { (positive) } & \\
1.93 & \text { days }\end{array}$ \\
\hline $0.2 \quad \mathrm{~mm} \mathrm{~s}^{-2}$ & $\begin{array}{l}\text { (negative) } \\
4.1 \\
\text { (positive) } \\
4.0\end{array}$ & $\begin{array}{ll}\text { (negative) } & \\
0.98 & \text { days } \\
\text { (positive) } & \\
0.97 & \text { days }\end{array}$ \\
\hline
\end{tabular}

Table 4 - Time required for lunar orbit plane precession

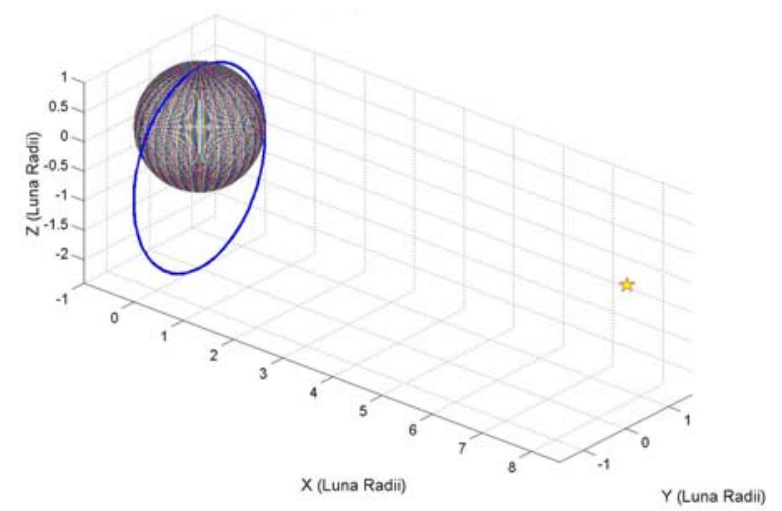

Figure 2 - Initial lunar orbit, selenocentric co-ordinates, solar position indicated

A further investigation has attempted to determine the time to shift the orbit perilune from the North Pole to South Pole. However, using a sail steering law to shift the orbit argument of pericentre results in the classical orbital elements shown in Figure 3 for the orbit in Figure 2 using a sail acceleration of $0.2 \mathrm{~mm} \mathrm{~s}^{-2}$. The argument of perilune is seen to vary significantly, corresponding to the desired rotation of the orbit. However, as time progresses the perilune altitude decreases significantly, suggesting that even an initial perilune altitude of $1000 \mathrm{~km}$ would impact the surface due to the increase in orbit eccentricity. Therefore, the authors conclude that such an orbit may not be practical without a complex orbit optimisation procedure, extremely accurate navigation and precision control. 

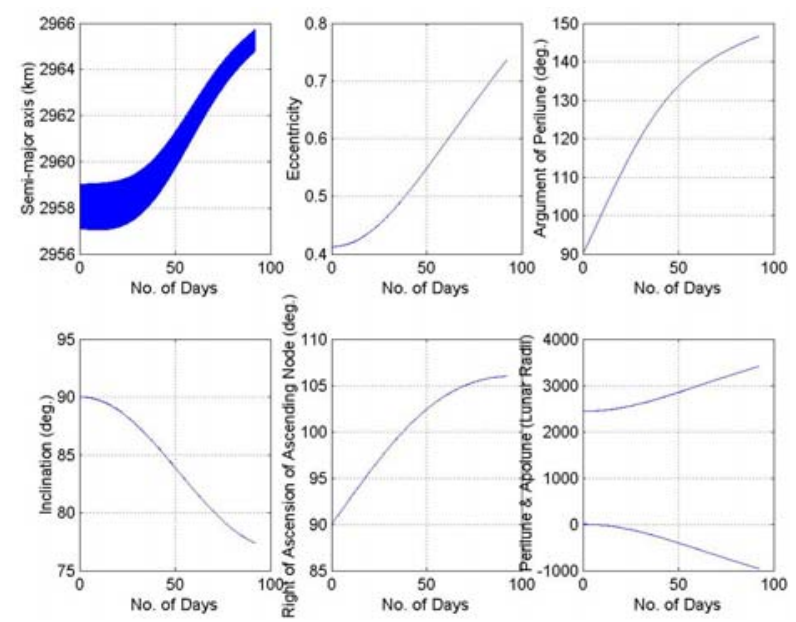

Figure 3 - Classic orbit elements and perilune/apolune altitudes

\subsection{4 -NEA Flyby Trajectories}

The Near Earth Objects Dynamic Site (NEODYS) was used to search for Near Earth Asteroids (NEA) with a semi-major axes between 0.8 and $1.2 \mathrm{AU}$, eccentricities less than 0.2 , and inclinations less than $2^{\circ}$. The orbits were then visualised using the NASA/JPL NEA orbit plotter and orbital elements obtained, including the mean motion and time of perihelion passage from which the asteroid state vector as a function of time was obtained. In the first instance, trajectories were generated using a characteristic acceleration of $0.2 \mathrm{~mm} / \mathrm{s}^{2}$, since trajectory optimisation is easier at higher accelerations. A genetic algorithm was used to generate an initial guess of the control angles for a sequential quadratic programming based optimizer (NPSOL) at arbitrary Earth departure dates. Table 5 shows the flyby times for a number of NEAs with the departure date used at $C_{3}=0$.

\begin{tabular}{|l|l|l|}
\hline $\begin{array}{l}\text { Asteroid } \\
\text { (designation) }\end{array}$ & $\begin{array}{l}\text { Earth } \\
\text { Departure } \\
\text { Date }\end{array}$ & $\begin{array}{l}\text { Flyby Time } \\
\text { (days) }\end{array}$ \\
\hline 2001 GP2 & January 1, 2010 & $895.6\left(0.2 \mathrm{~mm} \mathrm{~s}^{-2}\right)$ \\
\hline 1991 VG & January 1, 2015 & $361.0\left(0.2 \mathrm{~mm} \mathrm{~s}^{-2}\right)$ \\
\hline 2001 CQ36 & January 1, 2015 & $357.5\left(0.2 \mathrm{~mm} \mathrm{~s}^{-2}\right)$ \\
\hline 1999 VX25 & January 1, 2010 & $313.6\left(0.2 \mathrm{~mm} \mathrm{~s}^{-2}\right)$ \\
\hline 1999 VX25 & January 1, 2010 & $566.0\left(0.1 \mathrm{~mm} \mathrm{~s}^{-2}\right)$ \\
\hline
\end{tabular}

Table 5 - Selected NEA flyby times

The asteroid 1999 VX25 appears to be a good target of opportunity for a launch date near 2010. However, it is noted that a more detailed target search should be conducted in the future, since the quickest NEAs to reach will be more dependent on the Earth close approaches (listed on NEODYS) than on the orbital elements. Figure 4 shows a launch date scan across the 2009-2011 timeframe, where the optimal launch date appears to be for an Earth departure of March 10, 2011, with a flyby time of 285 days. The trajectory is shown in Figure 5, with flyby occurring on December 20, 2011. Figure 6 shows the (10 control segments) control profile of the cone and clock angles, with Figure 7 showing the evolution of the orbital elements.

Lastly, a trajectory was also produced for a characteristic acceleration of $0.1 \mathrm{~mm} \mathrm{~s}^{-2}$ with an arbitrary departure date of January 1, 2010, shown in Figure 8. The flyby time is 566 days, arriving on July 21, 2011. It can be seen that the lower characteristic acceleration leads to a double loop trajectory. 


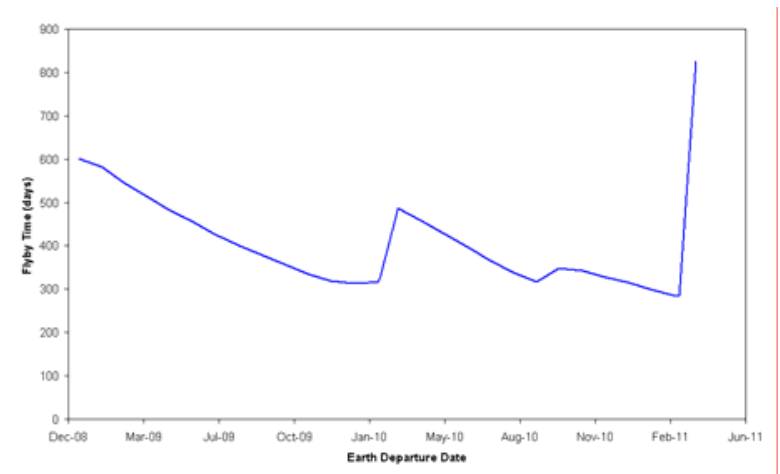

Figure $4-0.2 \mathrm{~mm} / \mathrm{s}^{2} 1999$ VX25 dep. date scan

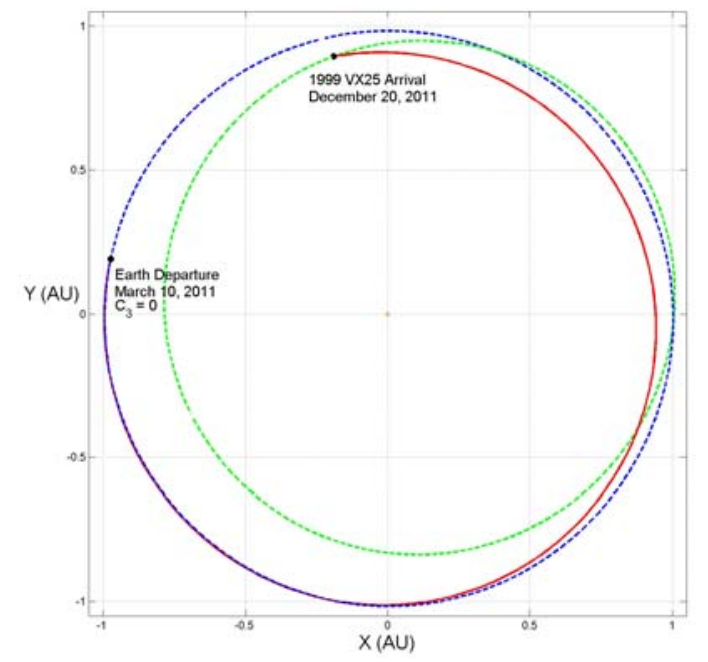

Figure $5-0.2 \mathrm{~mm} / \mathrm{s}^{2} 1999$ VX25 flyby trajectory
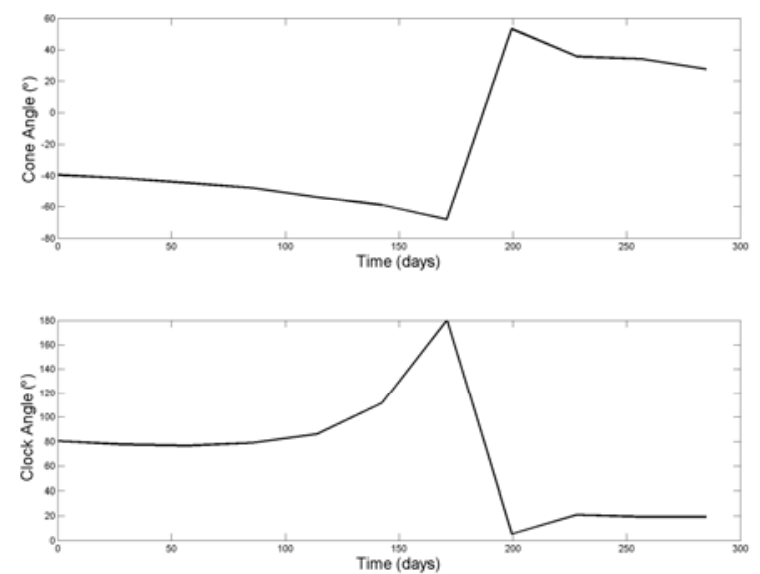

Figure 6 - $0.2 \mathrm{~mm} / \mathrm{s}^{2} 1999$ VX25 flyby control angle profile 

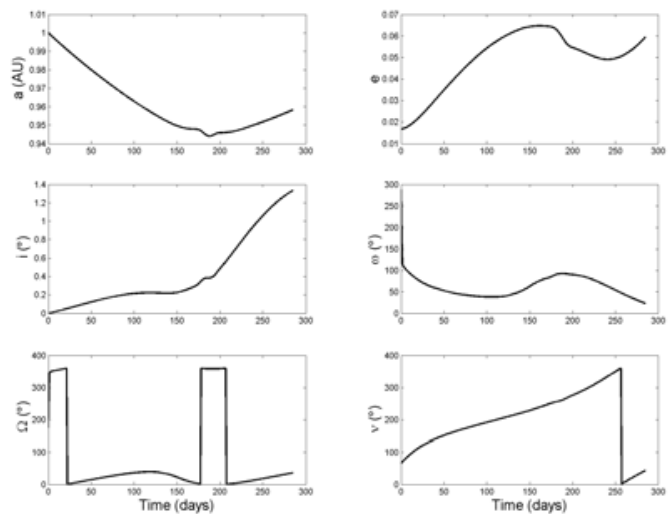

Figure $7-0.2 \mathrm{~mm} / \mathrm{s}^{2} 1999$ VX25 flyby orbital element evolution

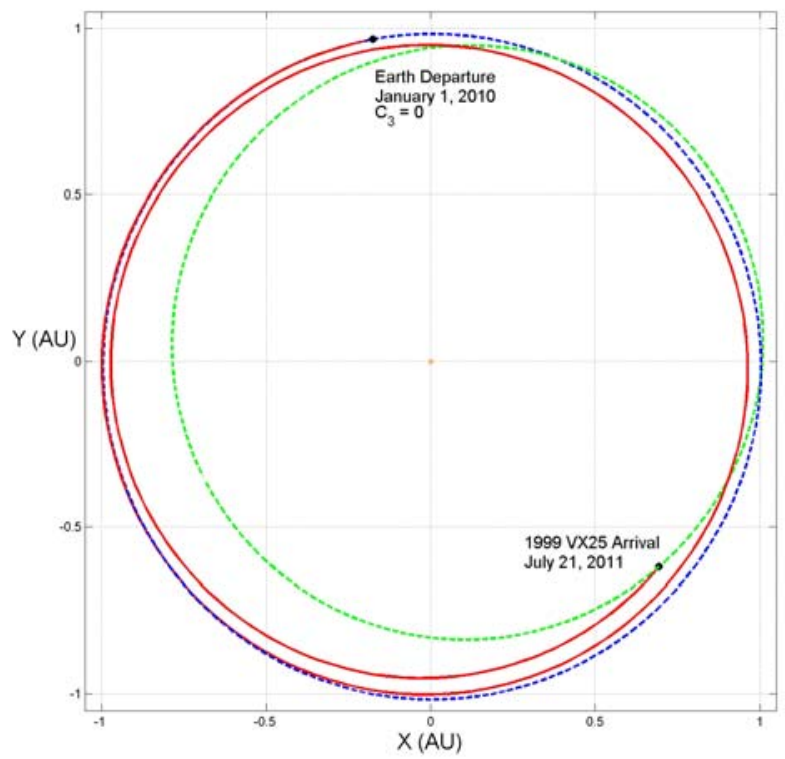

Figure $8-0.1 \mathrm{~mm} \mathrm{~s}^{-2} 1999$ VX25 flyby trajectory

\section{$\underline{6 \text { - Attitude Control }}$}

\section{$\underline{6.1 \text { - Attitude control requirements }}$}

The attitude control requirements for the solar kite can be summarised in Table 6 below.

\begin{tabular}{|l|c|}
\hline \multicolumn{1}{|c|}{ Features } & Comments \\
\hline Pointing knowledge & $1^{\circ}$ \\
\hline Rate range & 0 to $1 \mathrm{mrad} / \mathrm{s}$ \\
\hline $\begin{array}{l}\text { Max angular } \\
\text { acceleration }\end{array}$ & $40 \mathrm{nrad} / \mathrm{s}^{2}$ \\
\hline
\end{tabular}

Table 6 - Solar kite attitude control requirements

\section{$\underline{6.2 \text { Attitude control system }}$}

\subsubsection{Attitude sensing}

The main science camera the kite is equipped with will use the STAR-250 sensor chip but will otherwise be similar to the Space-X imager manufactured by CSEM [4] which has radiation-hardened optics with a choice of 
7.5, 45, 70, or 100 degree FOV. Supplementary attitude control camera(s) should use the same chip type. The STAR-250 chip is sufficiently radiation hard that it needs no shielding and a single set of frame-grabbing electronics can be switched between any number of the chips. Consequently each such supplementary 'camera' will mass only $\sim 30 \mathrm{~g}$.

The science camera will likely have a $7.5^{\circ} \mathrm{FOV}$, but the attitude control camera will have a $100^{\circ} \mathrm{FOV}$. The kite can then perform accurate attitude sensing without the need for on-board star tables and starfield matching algorithms, and potentially even without the need for non-volatile memory, an onboard battery or real-time clock.

Use of a wide-angle camera for attitude control has four advantages:

1. The same guide stars continue to be used even when the kite is changing orientation by substantial amounts.

2. The kite can be oriented so guide stars remain visible to the wide-angle camera even during low lunar passes, when the science camera is being pointed at ground targets.

3. Very bright stars can be used as guide stars. Within a $100^{\circ}$ field of view there are typically five firstmagnitude and seven second-magnitude stars. Such stars can be tracked successfully even in the presence of stray light from planetary objects etc. The camera does not require any light baffles as long as it is pointing in the hemisphere away from the Sun.

4. 3-axis sensing can be provided using a single camera. Sensing accuracy is $\sim 0.2^{\circ}$.

\subsubsection{Attitude actuation}

Three types of attitude control mechanism will be used on the solar kite:

- Heated wire photon emitters: Located at the boom tips, these will provide $3.3 \mathrm{nN} / \mathrm{W}$ thrust. Using the maximum $10 \mathrm{~W}$ power available, these could produce $40 \mathrm{nNm}$.

- Piezo-electric actuators: These will be connected to the support struts and will allow the central payload module to be moved by up to $~ 1 \mathrm{~mm}$ in any direction within the plane of the kite. $40 \mathrm{nNm}$ are obtained by displacing the payload by one millimetre.

- Heated support struts: The support struts can be heated, so causing them to expand and move the payload by up to one centimetre. This technique gives $400 \mathrm{nNm}$ for a displacement of one centimetre.

The heated wire photon emitters will be used primarily for steering, while the other two methods will be used primarily to ensure COM-COP alignment

A turn rate of $<<1 \mu \mathrm{rad} / \mathrm{s}^{2}$ is sufficient for steering if the kite does not enter continuously low orbit about the Earth or Moon. Consequently, in principle any of the above methods is more than adequate. However, in practice it cannot be guaranteed that the kite's COM and COP will be perfectly aligned after deployment. A misalignment of as little as one millimetre could require all of the kite's power to compensate it if only photon emitters are used.

A misalignment greater than one centimetre could render the kite uncontrollable even by heated strut COM displacement.

The low mass piezolectric actuators identified in [5] could achieve more authoritative COM displacement, and without the need for continuous power. They have been vacuum tested but are not yet fully space-qualified as they have not been radiation tested.

A further consideration is that neither of the COM movement methods can provide Z-axis torque, and the heated strut method is slow because although it requires little power to heat the dural struts in vacuo, they are 
also slow to cool (about 4 seconds per degree). It is therefore optimal to use a combination of all three methods.

\section{$\underline{6.3 \text { - External interactions with attitude control system }}$}

Three possible candidates for external interaction with attitude control have been identified:

- $\quad$ Tidal torque forces can be up to $\sim 1 \mu \mathrm{rad} / \mathrm{s}^{2}$, but are exactly predictable, so the attitude control system can set up an orientation on approach to perigee or perilune.which will yield the desired perigee or perilune orientation after tidal torque operates, without needing to counter the maximum tidal torque directly.

- Micrometeoroid strikes on the sail can produce a maximum spin $<10 \mathrm{nrad} / \mathrm{s}$, because micrometeoroids $>1 \mu \mathrm{m}$ in diameter will penetrate the sail rather than being stopped by it. Micrometeoroids $<1 \mu \mathrm{m}$ in diameter, by contrast, donate all their momentum to the structure. Such maximal events might be expected about once per day. Strikes by larger micrometeoroids on thicker structural elements could theoretically impart larger spins, but such events will be extremely rare. In general micrometeoroid effects can be ignored.

- Atmospheric drag could, in principle, impart spin due to COM-COP misalignment. With $1 \mathrm{~cm}$ misalignment, the worst-case $0.1 \mathrm{~m} / \mathrm{s}^{2}$ drag identified in section 5.2 could in theory spin the kite at 10 $\mathrm{mrad} / \mathrm{s}^{2}$. However this would not be cumulative: in 20 seconds the kite would have turned $90^{\circ}$ and there would be a restoring torque. The kite could nevertheless emerge from an atmospheric encounter turning at $\sim 0.1 \mathrm{rad} / \mathrm{s}$ about an unpredictable combination of the $\mathrm{X}$ and $\mathrm{Y}$ axes.

To avoid the last situation occurring, it will be advisable to perform COM-COP alignment between kite deployment and the first subsequent atmospheric interaction, by deploying the kite shortly after perigee. If the kite is not in sunlight at perigee, it will be impossible to directly control the temperature of the wires holding the central payload. Shadowing may cause them to cool, atmospheric friction to heat slightly (although it will be $<100 \mathrm{~W} / \mathrm{m}^{2}$ even in the worst case). The piezolectric actuators should therefore be used before eclipse to arrange that the COM and COP will be aligned at perigee as accurately as can be predicted. This should reduce the post-perigee turn rate to $\sim 0.01 \mathrm{rad} / \mathrm{s}$, which can be damped in $\sim 20$ minutes by use of the piezoelectric actuators for central mass displacement.

\section{$\underline{6.4 \text { - Attitude control performance assessment }}$}

An AOCS performance assessment has been made by EADS Astrium. The analysis below was performed as for the 4 tip-mounted canted thrusters firing in pairs, because the software used was configured for this situation. Further analysis will be required to factor in the slower-response, but more power-economical, heated wire method which is preferable at times when high pointing fidelity is not required.

The solar kite's axes and moments of inertia are as follows:

\begin{tabular}{|l|c|}
\hline \multicolumn{1}{|c|}{ Features } & Comments \\
\hline Size & $2.10 \times 2.52 \mathrm{~m}$ \\
\hline Inertia of axis normal, Iz & $0.038 \mathrm{kgm}^{2}$ \\
\hline Inertia of axes planar, Ix & $0.024 \mathrm{kgm}^{2}$ \\
\hline Inertia of axes planar, Iy & $0.014 \mathrm{kgm}^{2}$ \\
\hline
\end{tabular}

Table 7 - Kite Moments of Inertia

\section{$\underline{7 \text { - Tracking }}$}

The kite will not carry a standard transponder. It is proposed that a mix of tracking techniques be used, as follows: 


\section{1 - During initial ascent from GTO toward lunar distance}

The kite can be tracked optically from the ground. When in sunlight the kite will have an apparent visual magnitude ranging from about 5 at initial GTO perigee to 18 at lunar distance. An amateur 8-inch CCD telescope can detect $20^{\text {th }}$ magnitude stars, so an expensive telescope system will not be necessary.

Lateral detection error will be about 400 metres at GEO increasing to 4 kilometres at lunar distance. Perigee altitude will be determined by taking cross-bearings, apogee by combining this information with the kite's current orbital period.

It is anticipated that daily position fixes will provide sufficient accuracy. Since the kite has no propellant constraints, high navigational accuracy is necessary only in close flyby situations.

\section{2 - As the kite starts to approach to the Moon}

The kite's science camera will image the Earthlit lunar limb against the stellar background, and return the image to the ground for processing. This camera has an angular resolution of $0.015^{\circ}$, which will enable a crossbearing of accuracy about $3 \times 10^{-4}$ radians relative to known lunar topography to be obtained, giving positional accuracy of e.g. $1 \mathrm{~km}$ when 30,000 kilometres from the lunar surface.

\section{3 - As the kite makes low-perilune flybys}

When in close orbit about the Moon, comparison of a ground shot with the Lunar Surveyor database will give a lateral position fix to within about 2 metres. Apparent speed of landscape gives altitude above lunar surface with an accuracy that is proportional to the altitude. For example if two pictures are taken at an interval that should cause them to be relatively displaced by 250 pixels if the kite is at the intended altitude, then each extra pixel displacement corresponds to a $0.4 \%$ undershoot in altitude.

\section{4 - Approaching a NEO asteroid}

Continuously monitoring sightline spin rate allows a chosen miss distance to be selected during a NEO asteroid fly-by. A sight-line spin rate of zero corresponds to direct impact. The (approximate) distance of the approaching asteroid is known from ground observations, so by selecting a small non-zero sightline spin rate an appropriate miss distance can be selected. This is well known from missile guidance theory.

As a general point high accuracy navigation is only required when the kite is in the close vicinity of an object it can image.

During the development of navigational algorithms it would be sensible to test them with deliberate degradation to simulate navigational inaccuracies. Running such tests in conjunction with high fidelity solar sail trajectory modelling software will establish the maximum interval that can be allowed between position fixes without cumulative navigational inaccuracies significantly increasing mission times.

\section{$\underline{8 \text { - Solar kite data and communications }}$}

\section{$\underline{8.1 \text { - Communications systems }}$}

An RF system of about 2W output power is required, capable of transmitting data at up to 300 bps.

Mass considerations rule out carrying a standard spacecraft transponder. All those identified in TN2 have masses of hundreds of grams or more. However, electronics which can transmit and receive data at power of up to a few watts which weigh only a few grams are now mass-produced for mobile communications devices and similar. These are vastly lighter, in particular as regards their SSPA (solid state power amplifier) stages than traditional spacecraft components which tend to mass around $300 \mathrm{~g} / \mathrm{W}$. 
Most of the kite's components are radiation-hard and require little if any shielding. However there is a volume of about $20 \mathrm{~cm}^{3}$ at the centre of the payload sphere which will have intrinsic radiation insulation equivalent to $\sim 2.5 \mathrm{~g} / \mathrm{cm}^{2}$ of aluminium due to the components surrounding it. This reduces the radiation dose for items placed here to $~ 500$ rads/year. Experience from the original Amsats onward shows that there is an excellent chance of standard electronic components (with the exception of devices intrinsically vulnerable to single-event latchup) functioning well after cumulative doses much greater than $1 \mathrm{krad}$.

At the time of writing, the lightest commercially available mobile communication units mass 65-70 grams including battery, antenna and outer casing. A realistic estimate for the mass of the circuit board and antenna is $40 \mathrm{~g}$.

\section{$\underline{8.2 \text { - Data rate vs. payload requirements }}$}

The fundamental requirement to return data is the ability to transmit a 512 x 512 pixel image. The calculations below apply to a kite with $200 \mathrm{~mW}$ RF output power (as applies in a non-Sun-facing situation) transmitting from lunar distance $(400,000 \mathrm{~km})$ to a $10 \mathrm{~m}$ diameter ground antenna.

The data rate scales in linear proportion to the RF output power available. If $2 \mathrm{~W}$ output power is available, as when the kite faces the Sun, the data rate becomes 380 bps. This corresponds to about 2 hours to transmit a 512 x 512 pixel image from lunar distance.

\section{$\underline{9 \text { - Solar kite power system design }}$}

\section{$\underline{9.1 \text { - Power generation/storage systems }}$}

Thin film solar cells of mass $3 \mathrm{~g} / \mathrm{W}$ (even after radiation degradation) will be used in two arrays:

- An omnidirectional array on the outer surface of the payload module. This will have area $360 \mathrm{~cm}^{2}$, mass $30 \mathrm{~g}$ and will generate $2 \mathrm{~W}$ in all orientations (except in eclipse).

- A planar set of cells of the same mass and area will generate an additional $10 \mathrm{~W}$ when Sun-facing.

It is hoped that a requirement for battery storage can be avoided. However if the OBDHS requires sleep mode power with clock-driven or external interrupt reactivation, power consumption during eclipse will be $\sim 1 \mathrm{~mW}$. Maximum eclipse time will be $\sim 30$ minutes, and micropack batteries mass $\sim 20 \mathrm{~g} / \mathrm{Wh}$, so the minimum available size 0.2g EADS CRC micropack should be sufficient.

\subsection{Power required for subsystems and payload}

In order to minimize or avoid the need for power conditioning, power generation is divided as follows:

The cells surrounding the central payload are wired in series in sets in such a way that each such set generates $\sim 6 \mathrm{~V}$ irrespective of orientation, i.e. it consists of 12 cells pointing in different directions. The sets are connected in parallel to power the central electronics module including the cameras and the OBDHS, but excluding the high-power RF sender.

The flat array of cells is wired in a series/parallel combination to generate the optimal drive voltage for the high-power (2 W output) RF sender when it is exactly Sun-facing.

Either array of cells can also be connected to any of the photon thrusters at any given time. Being simple thermal emitters, these function at any voltage.

Not all of the kite's systems are run simultaneously. In particular no more than one of the following occurs at 
one time:

1. Transmission of 'high rate' RF data.

2. Performance of a 'high-acceleration' 10W Z-axis roll using photon thrusters.

These functions use the flat array.

Moreover only one of the following functions is ever performed at one time:

1. Piezoelectric driver actuation. (Power required only to change position; no power required to retain selected displacement.)

2. $\quad$ Performance of a 'low-acceleration' 2W Z-axis roll using photon thrusters

3. Any activity by central electronics package.

These functions use the central payload array

Thus there is never a requirement for the central array to provide more than $2 \mathrm{~W}$ of power, or the flat array more than $10 \mathrm{~W}$.

The most extreme power demand situation that can arise is if, after initial deployment, the kite is spinning about its $\mathrm{Z}$ axis at $3 \%$ s edge-on to the Sun. In this case only $2 \mathrm{~W}$ of power would be available to cancel out the roll. In this circumstance, after the situation has been analysed, a command must be sent to direct all of the $2 \mathrm{~W}$ of power available to the appropriate thrusters for almost all of the time until the roll has been stopped.

Total array mass (assming a 20\% structural allowance in each case) is

Flat array: $\quad 30 \mathrm{~g}+20 \%=36 \mathrm{~g}$

Spherical array $30 \mathrm{~g}+20 \%=36 \mathrm{~g}$ 


\section{0 - Budgets}

Figure 9 gives shows a schematic of the solar kite, while Figure 10 portrays a deployed solar kite in Earth orbit.

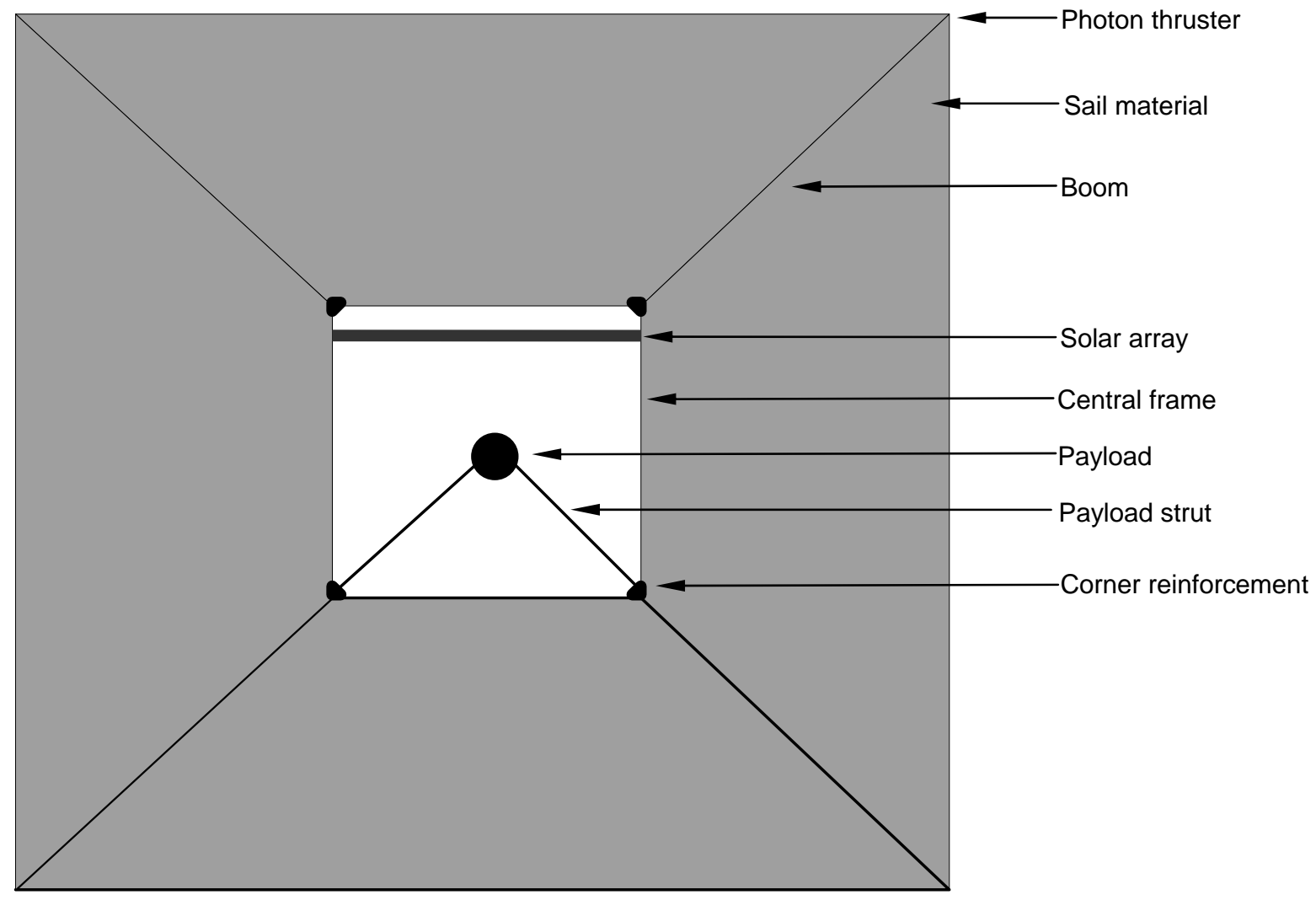

Figure 8 - Schematic of solar kite

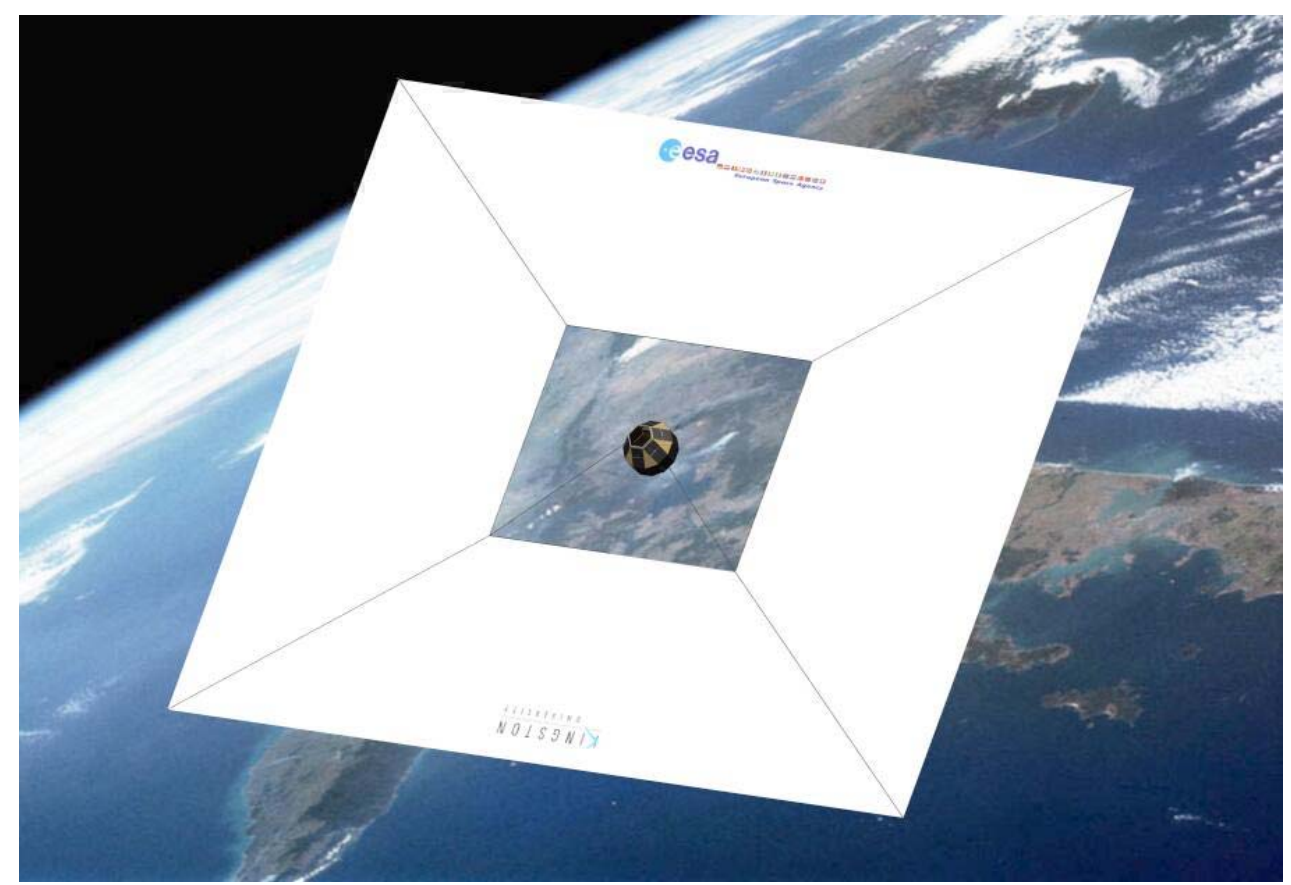

Figure 9 - Deployed solar kite in Earth orbit 
$\underline{10.1 \text { - Final mass budget }}$

\begin{tabular}{|c|c|c|c|}
\hline Item & $\begin{array}{l}\text { Unit } \\
\text { mass }\end{array}$ & Quantity & Mass (g) \\
\hline \multicolumn{4}{|l|}{ Solar Kite } \\
\hline CFE rod, ø 2mm & $5.6 \mathrm{~g} / \mathrm{m}$ & $7.44 \mathrm{~m}$ & 42 \\
\hline PET film, $2 \mu \mathrm{m}$ & $\begin{array}{l}2.87 \\
\mathrm{~g} / \mathrm{m}^{2}\end{array}$ & $4.70 \mathrm{~m}^{2}$ & 14 \\
\hline $\begin{array}{l}\text { Boeing Spectrolab } \\
\text { thin film solar cells }\end{array}$ & $\begin{array}{c}84 \\
\mathrm{mg} / \mathrm{cm}^{2}\end{array}$ & $360 \mathrm{~cm}^{2}$ & 36 \\
\hline Dural rod, ø 2mm & $8.8 \mathrm{~g} / \mathrm{m}$ & $1.06 \mathrm{~m}$ & 10 \\
\hline $\begin{array}{l}\text { STEM } \\
\text { hinges/reinforcement }\end{array}$ & $2.5 \mathrm{~g}$ & 4 & 10 \\
\hline Wiring & $10 \mathrm{~g}$ & 1 & 10 \\
\hline $\begin{array}{l}\text { Heated wire photon } \\
\text { emitter }\end{array}$ & $4 \mathrm{~g}$ & 4 & 16 \\
\hline \multicolumn{3}{|c|}{ Solar Kite Sub-Total } & 138 \\
\hline \multicolumn{4}{|l|}{ Payload module } \\
\hline $\begin{array}{l}\text { Wiring, circuit board } \\
\text { incl. power } \\
\text { conditioning, battery }\end{array}$ & $\begin{array}{l}25 \mathrm{~g} \\
\text { (estd.) }\end{array}$ & 1 & 25 \\
\hline thin film solar cells & $\begin{array}{c}84 \\
\mathrm{mg} / \mathrm{cm}^{2}\end{array}$ & $360 \mathrm{~cm}^{2}$ & 36 \\
\hline $\begin{array}{ll}\text { OBDH } & \text { electronics } \\
\text { module } & \\
\end{array}$ & $\begin{array}{l}25 \mathrm{~g} \\
\text { each }\end{array}$ & 1 & 25 \\
\hline $\begin{array}{l}\text { Fillfactory STAR250 } \\
\text { CMOS APS CCD }\end{array}$ & $\begin{array}{l}30 \mathrm{~g} \\
\text { each }\end{array}$ & 2 & 60 \\
\hline Radio transceiver & $40 \mathrm{~g}$ & 1 & 40 \\
\hline Optics and structure & $\begin{array}{c}30 \mathrm{~g} \\
\text { per } \\
\text { imager }\end{array}$ & 2 & 60 \\
\hline Piezoelectric drivers & $2 \mathrm{~g}$ & 2 & 4 \\
\hline \multicolumn{3}{|c|}{ Payload module sub-total } & $\begin{array}{c}250+20 \% \\
\text { structural } \\
\text { allowance = } \\
300 \mathrm{gm}\end{array}$ \\
\hline & & TOTAL & $438 \mathrm{gm}$ \\
\hline
\end{tabular}

Table 8 - Mass budget

The $40 \mu \mathrm{N}$ available thrust from a kite of minimum dimensions will give a nominal acceleration of $0.09 \mathrm{~mm} / \mathrm{s}^{2}$. However from a maximum height microsat payload bay, up to twice the sail area could be obtained, which would allow a trade-off between additional payload mass/contingency allowance and higher acceleration.

\subsection{Final launch volume}

A pair of kites, with its container, fits within a $60 \mathrm{~cm}$ x $60 \mathrm{~cm}$ x $71 \mathrm{~cm}$ ASAP-5 microsat bay. However an extra height bay, up to $150 \mathrm{~cm}$, can be used advantageously if available.

\subsection{Final deployed dimensions}

210 x $252 \mathrm{~cm}$ minimum (up to 450 x $252 \mathrm{~cm}$ in extra height bay)

\subsection{Final power budget}

Not all of the solar kite sub-systems will be operating simultaneously. The piezoelectric drivers require power only to change their position. 


\begin{tabular}{|c|c|c|c|}
\hline Item & $\begin{array}{c}\text { Power } \\
\text { reqd } \\
(W)\end{array}$ & $\begin{array}{c}\text { Power } \\
\text { prod. } \\
\text { (W) }\end{array}$ & Comment \\
\hline \multicolumn{4}{|l|}{ Solar Kite } \\
\hline $\begin{array}{lll}\begin{array}{l}\text { Thin } \\
\text { cells }\end{array} & & \\
\end{array}$ & - & 10 & $\begin{array}{l}\text { When not eclipsed } \\
\text { and pointing at Sun }\end{array}$ \\
\hline Heated Dural struts & $0-1$ & - & As required \\
\hline $\begin{array}{l}\text { Heated wire photon } \\
\text { emitter }\end{array}$ & $0-10$ & - & As required \\
\hline \multicolumn{4}{|l|}{ Payload module } \\
\hline $\begin{array}{l}\text { Thin film solar } \\
\text { cells }\end{array}$ & - & 2 & $\begin{array}{l}\text { When not eclipsed } \\
\text { irrespective of kite } \\
\text { orientation }\end{array}$ \\
\hline $\begin{array}{l}\text { OBDH electronics } \\
\text { module }\end{array}$ & $\begin{array}{l}\text { up to } \\
1.5\end{array}$ & - & \\
\hline $\begin{array}{l}\text { Fillfactory } \\
\text { STAR250 CMOS } \\
\text { APS CCD }\end{array}$ & 0.35 & - & As required \\
\hline Radio transceiver & 10 & - & As required \\
\hline $\begin{array}{l}\text { Piezoelectric } \\
\text { drivers (2) }\end{array}$ & $\begin{array}{c}1.9 \\
\text { each }\end{array}$ & - & $\begin{array}{l}\text { Only briefly during } \\
\text { on-orbit } \\
\text { commissioning }\end{array}$ \\
\hline TOTALS & $\mathrm{n} / \mathrm{a}$ & 12 & $\begin{array}{l}\text { Maximum when not } \\
\text { eclipsed and } \\
\text { pointing at Sun }\end{array}$ \\
\hline
\end{tabular}

Table 9 - Power Budget

\section{$\underline{10.5 \text { Final communication budget }}$}

Table 10 lists the times to transmit images and navigational data at different combinations of range and ground antenna size, allowing for $15 \%$ communications overhead. RF transmission output power is $2 \mathrm{~W}$ using an omnidirectional (0 dB gain) antenna.

\begin{tabular}{|l|l|l|l|}
\hline Range $(\mathrm{km})$ & $\begin{array}{l}\text { Ground } \\
\text { antenna } \\
\text { diameter } \\
(\mathrm{m})\end{array}$ & $\begin{array}{l}\text { Attitude data } \\
\text { transmission } \\
\text { time }\end{array}$ & $\begin{array}{l}\text { Image } \\
\text { transmission } \\
\text { time (no } \\
\text { compression) }\end{array}$ \\
\hline Lunar 400,000 & 10 & 5 seconds & 2.2 hours \\
\hline NEO 4,000,000 & 10 & 8 minutes & 10 days \\
\hline NEO 4,000,000 & 100 & 5 seconds & 2.2 hours \\
\hline
\end{tabular}

Table 10 - Data Transmission Times

\section{$\underline{11-\text { Conclusions }}$}

While detailed work remains to be done, it appears extremely likely that solar kites 2-4 metres in diameter, and carrying useful payloads of the order 0.1-1.0 kg, could be launched with almost every ASAP-5 bus at very low cost, and could perform valuable missions out to lunar range and beyond.

\section{$\underline{12-\text { References }}$}

1. C Jack and C S Welch, Solar Kites - Small Solar Sails with No Moving Parts, Acta Astronautica, Vol 40/2-8, pp.137142, October 1997, ISSN 0094-57613

2. C Jack and C Welch, Solar kites: cheap self-propelled imagers for near-earth exploration, $54^{\text {th }}$ International Astronautical Congress, Bremen, Germany, October 2003

3. Fillfactory image sensors web site, accessed 22 March 2004, www.fillfactory.com/htm/products/htm/star250/ star250.htm

5. Micro-Cameras \& Space Exp SA (SPACE-X) web site, accessed 2 June 2003, www.space-x.ch/ microcamera.htm 
6. Micropulsesystems web site, accessed 30 March 2004, www.micropulsesystems.com 